\title{
Применение DC / DC-преобразователей QA151 от Mornsun в схемах управления затворами мощных транзисторов для инверторов солнечных батарей
}

В. Ежов

УДК 621.314 | ВАК 05.27 .01

По мере увеличения спроса на возобновляемые источники энергии все более востребованными становятся новые технологии генерирования электроэнергии. Среди коммерчески доступных технологий наиболее важное место занимает преобразование солнечной энергии с помощью фотоэлектрических станций. Ключевой элемент фотоэлектрической системы генерирования электроэнергии инвертор, который преобразует постоянный ток солнечных батарей в переменный ток, передаваемый в общую электросеть. При проектировании схем управления мощными IGBT, используемых в инверторных системах, следует учитывать ряд специфических требований, которые обеспечивают надежную и безопасную работу системы. В статье рассмотрен пример построения схемы управления ICBT с использованием DC/DC-преобразователей QA151 от Mornsun.

фотоэлектрической системе солнечные батареи генерируют энергию постоянного тока, которая посредством инвертора преобразуется в энергию переменного тока и передается в электросеть для снабжения домохозяйств, промышленных предприятий или используется для заряда батарей в системе аккумулирования энергии с помощью так называемого двунаправленного инвертора (рис. 1). Система снабжает

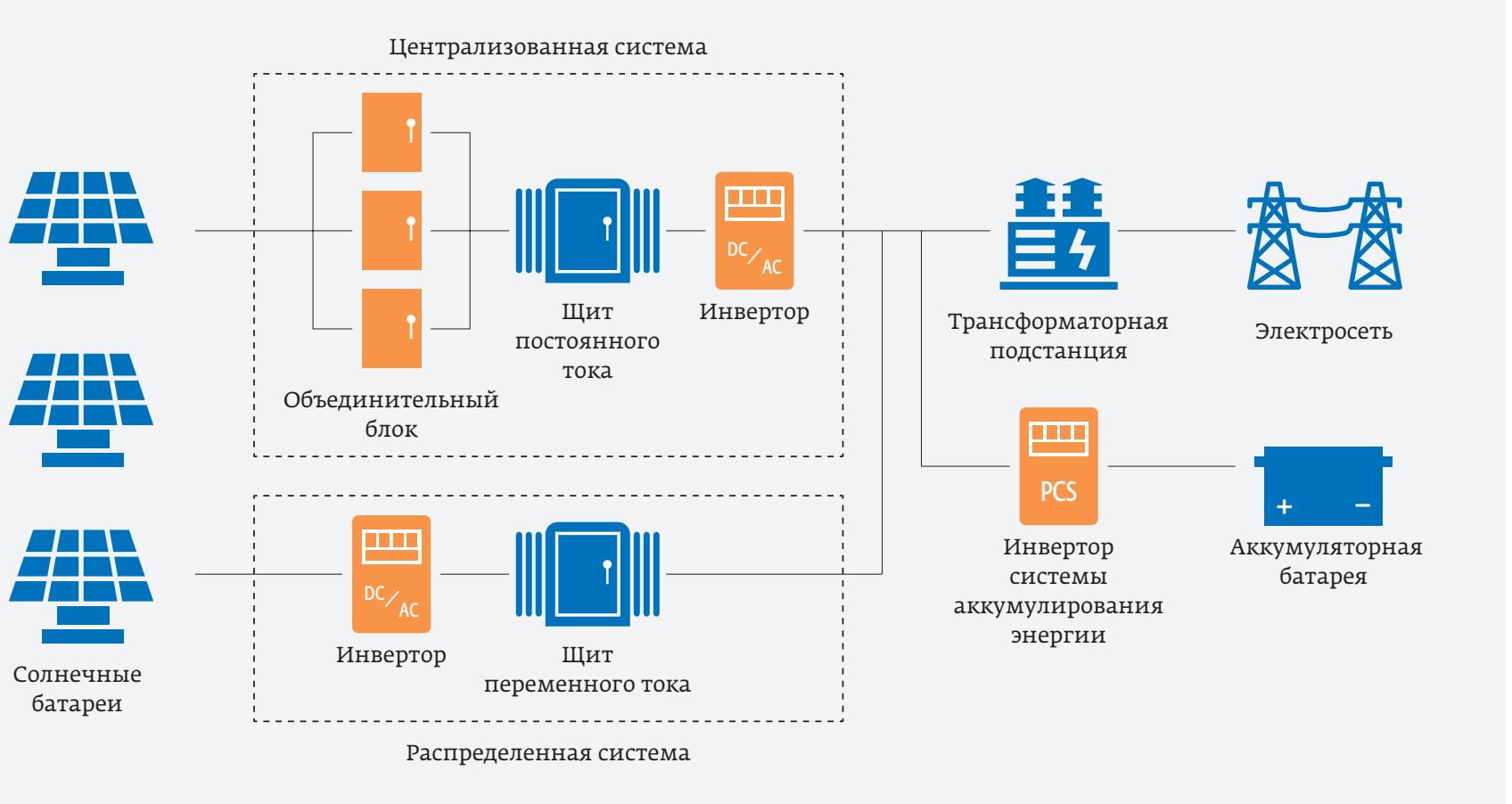

Рис. 1. Блок-схема фотоэлектрической системы генерации электроэнергии 
электроэнергией потребителей на основе баланса предложения и спроса.

Как в централизованной, так и в распределенной сети электроснабжения инвертор является ядром фотоэлектрической системы генерирования электроэнергии. Важнейшая задача при проектировании высоковольтных и высокомощных систем преобразования - обеспечить безопасное и надежное переключение мощных ключевых элементов, в качестве которых обычно используют мостовые схемы на IGBT. Поэтому нужно обеспечить стабильную работу блока управления IGBT и добиться высоких характеристик изоляции между блоком управления и опасными электрическими цепями.

Рассмотрим пример построения инверторной системы (рис. 2). Как правило, на входе такой системы используется DC/ DC-преобразователь (в данном случае PV60-27D1215) для преобразования напряжения шины питания постоянного тока в напряжение 24 B DC для питания блока управления. Напряжение изоляции такого DC / DC-преобразователя должно быть не менее 4000 В АС, чтобы обеспечить надежную развязку между высоковольтной шиной питания и схемой блока управления. Между IGBТ и системной платой управления включен драйвер IGВТ с высокими характеристиками изоляции для стабильной и безопасной работы основного блока управления.

Блок управления IGBT применяется преимущественно для развязки, передачи и усиления импульсных сигналов, чтобы обеспечить надежное управление мощными IGBT. При проектировании схемы управления следует учитывать ряд специфических требований.

1. В блоке инверторной системы широко используются полномостовые схемы включения IGBT, которые исключают сквозную проводимость между IGBT верхнего и нижнего плеча, возникновение короткого замыкания при высоких и низких напряжениях. Поэтому необходимое требование - применение в таких системах надежной, помехоустойчивой микросхемы управления драйвером IGBT.

2. Особенность работы IGBT заключается в том, что емкость перехода транзистора $C_{g e}$ заряжается или

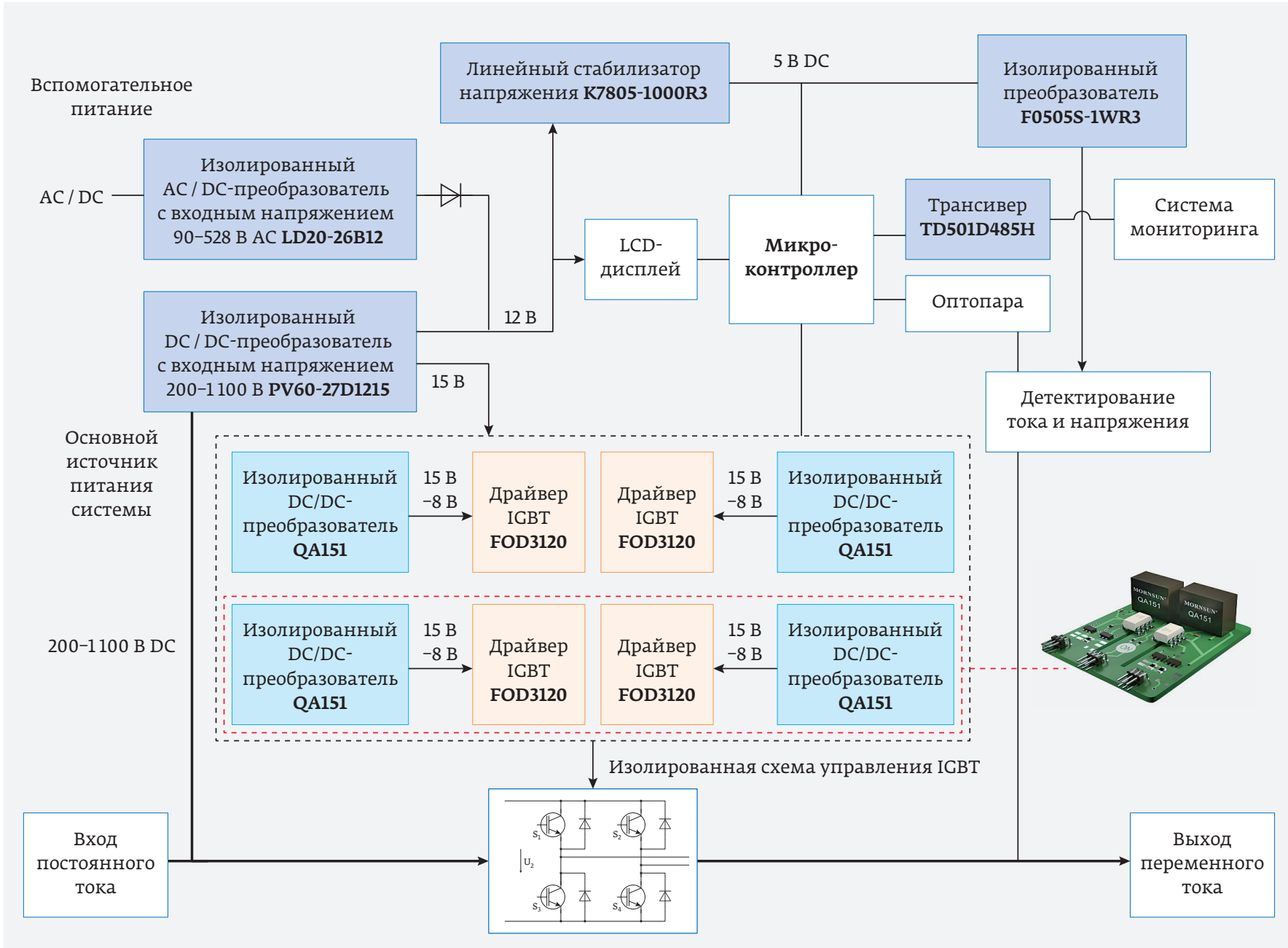

Рис. 2. Блок-схема инверторной системы 
разряжается при каждом включении или выключении IGBT. Поэтому DC / DC-преобразователь в схеме драйвера затвора должен обеспечивать асимметричное выходное напряжение как положительной, так и отрицательной полярности, а также соответствовать требованиям по переходным токам заряда и разряда емкости перехода, чтобы гарантировать быстрое включение и выключение IGBT.

3. При преобразовании высокого напряжения постоянного тока в переменное напряжение электросети во время быстрого включения и выключения IGBT генерируются высокочастотные помеховые сигналы большой амплитуды. Поэтому схема управления должна быть помехоустойчивой, обеспечивать высокое напряжение изоляции и низкую емкость изоляции, чтобы гарантировать надежную работу и исключить передачу сигнала синфазной помехи на системную плату управления.

4. Работа IGBT в режиме больших токов и высоких напряжений вызывает значительное повышение температуры внутри системы в процессе преобразования напряжения. Поэтому DC/ DC-преобразователь схемы управления должен отличаться широким диапазоном рабочих температур.

Компания ON Semi разработала демонстрационную плату управления IGBT, которая отвечает перечисленным требованиям. Рассмотрим принцип ее работы (рис. 3). Как показано на схеме, точки G1 и G2 подключены к затворам транзисторов IGBT, а на вывод 2 микросхемы FOD3120 подается сигнал управления. Когда уровень сигнала управления высокий, на выходе FOD3120 формируется напряжение высокого уровня, прп-транзистор 2\$C5569 включается, а рпр-транзистор 2SA2016 отключается. При этом выход положительного напряжения + $V_{0}$ модуля QA151 подключается к затвору Gl или G2, и IGBT включается. Когда уровень сигнала управления низкий, на выходе FOD3120 также формируется напряжение низкого уровня, nрп-транзистор 2SC5569 отключается, а рпр-транзистор 2SA2016 включается, выход отрицательного напряжения -V о модуля QA151 подключается к затвору, и IGBT отключается

DC/DC-преобразователь QA151 (рис. 4) от компании Mornsun предназначен для применения в драйверах IGBT. Благодаря реализованному режиму общего соединения после двух независимых выходов устройство представляет собой идеальное решение для питания микросхем драйверов IGBT FOD3120SD, а также транзисторов 2SC5569 и 2SA2016 от Компании ON Semi.

Модуль DC / DC-преобразователя QA151, в котором интегрированы функции драйвера, обеспечивает асимметричные выходные напряжения +15/-8,0 B DC, что минимизирует энергопотребление во время переключения

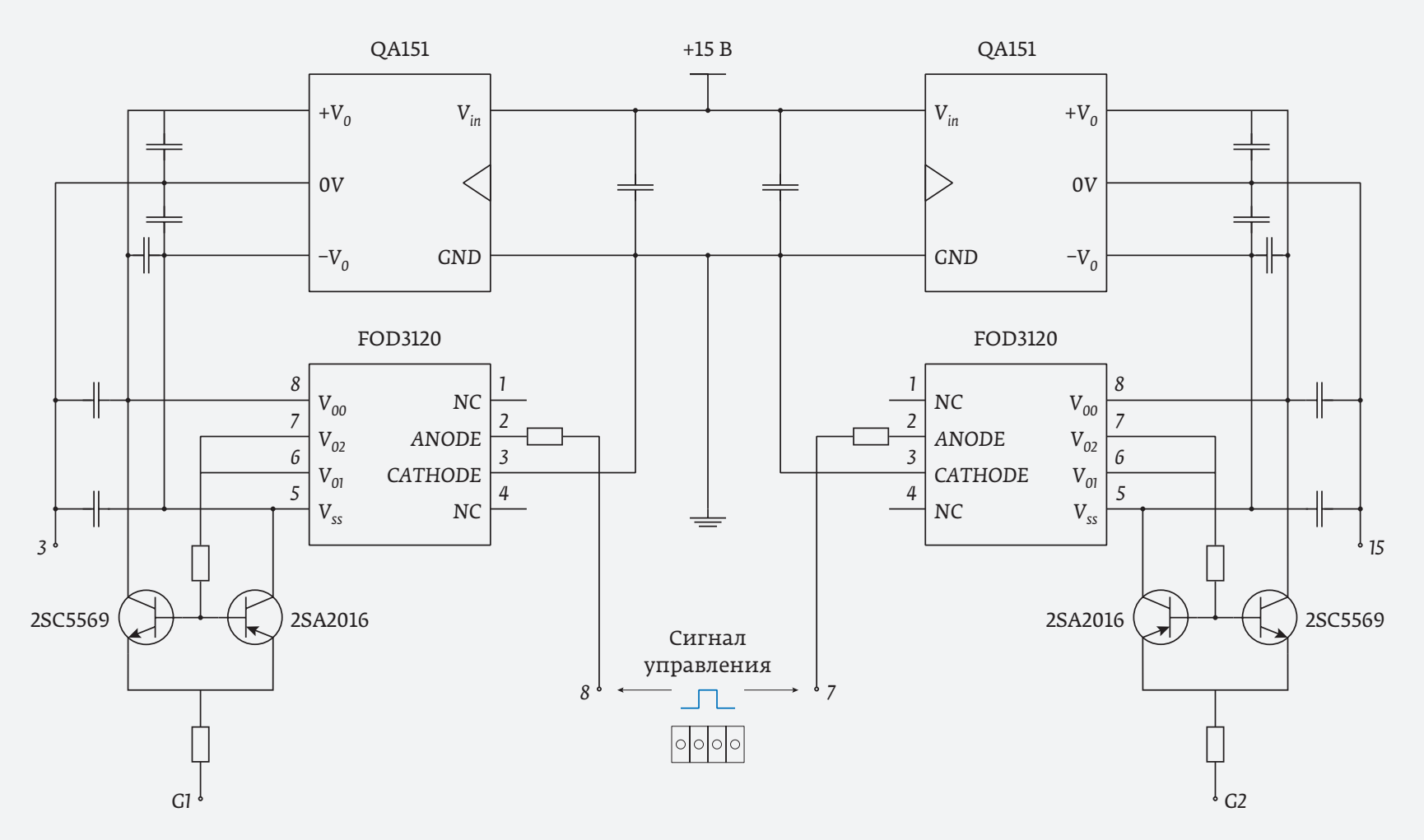

Рис. 3. Принципиальная схема демонстрационной платы управления компании ON Semi 


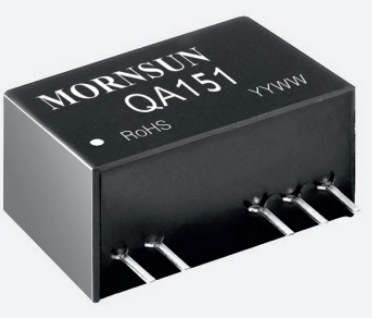

Рис. 4.

DC/ DC-преобразователь QA151 компании Mornsun

и отвечает требованиям быстрого включения или отключения IGBT

QA151 также обеспечивает широкий диапазон рабочих температур $\left(-40 . .105^{\circ} \mathrm{C}\right)$ и предлагается в компактном герметизированном 7-выводном корпусе типа SIP габаритами 19,5×9,8×12,5 мм. Это не только гарантирует соблюдение требований к конструкции плат на SIP-компонентах, но и упрощает компоновку системы.

Благодаря применению изолированного трансформатора напряжение изоляции модуля QA151 достигает 3000 В АС, что обеспечивает высокий уровень развязки цепей демонстрационной платы управления компании ON Semi. Кроме того, емкость изоляции QA151 составляет всего 6 пФ, поэтому плата управления высокоустойчива к воздействию помех. Выходной ток DC/ DC-преобразователя достигает 120 мА, а емкостная нагрузка превышает 200 мкФ, что удовлетворяет требованиям по мощности IGBT.

Более подробная информация об этом изделии и других продуктах компании Mornsun доступна на сайте www.mornsun-power.com.

\section{КНИГИ ИЗДАТЕЛЬСТВА «ТЕХНОСФЕРА»}

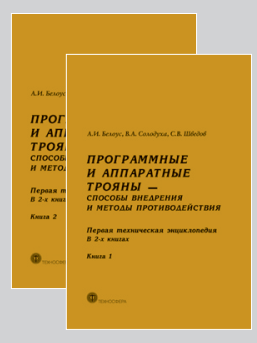

Цена за две книги 2400 руб.

\section{ПРОГРАММНЫЕ И АППАРАТНЫЕ} ТРОЯНЫ - СПОСОБЫ ВНЕДРЕНИЯ И МЕТОДЫ ПРОТИВОДЕЙСТВИЯ. ПЕРВАЯ ТЕХНИЧЕСКАЯ ЭНЦИКЛОПЕДИЯ

\author{
В 2-х книгах
}

\author{
Белоус А. И., Солодуха В. А., Шведов С. В. \\ Под общей редакцией Белоуса А. И.
}

\begin{abstract}
В двухтомнике исследован феномен программных и аппаратных троянов, которые фактически являются технологической платформой современного и перспективного кибероружия. В первой вводной главе показано, что развитие всех "обычных" и "новейших" видов вооружений дошло до такой стадии, что их использование на практике будет равносильно самоубийству начавшей войну стороны. Осознание этого факта привело к развитию информационно-технического оружия (кибероружия и нейрооружия). В последующих главах детально исследованы концепции, методы и примеры реализации этого вида оружия. Рассмотрены основные виды программных троянов, вирусов и шпионских программ, показан эволюционный путь развития аппаратных троянов от «ящиков» и «коробочек» до микросхем.

Книга ориентирована на специалистов по информационной безопасности, а также будет полезна всем интересующимся данной темой.
\end{abstract}

